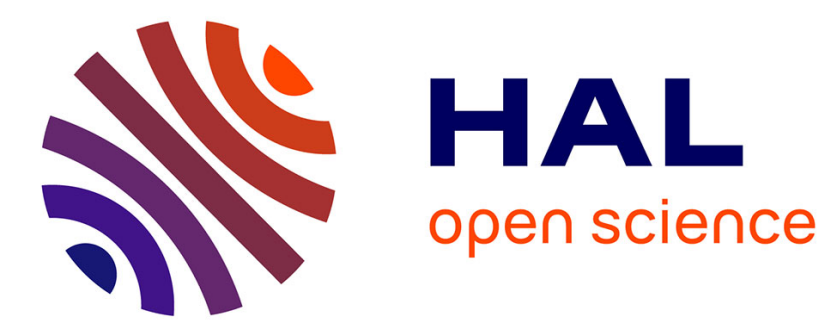

\title{
Inner cladding influence on large mode area photonic crystal fiber properties under severe heat load
}

Enrico Coscelli, Federica Poli, Romain Dauliat, Dia Darwich, A Cucinotta, S

Selleri, Kay Schuster, Aurélien Benoit, Raphaël Jamier, Philippe Roy, et al.

\section{- To cite this version:}

Enrico Coscelli, Federica Poli, Romain Dauliat, Dia Darwich, A Cucinotta, et al.. Inner cladding influence on large mode area photonic crystal fiber properties under severe heat load. Photonics West Conference, SPIE, Feb 2016, San Francisco, United States. pp.9728-80. hal-01239439

\author{
HAL Id: hal-01239439 \\ https://hal.science/hal-01239439
}

Submitted on 7 Dec 2015

HAL is a multi-disciplinary open access archive for the deposit and dissemination of scientific research documents, whether they are published or not. The documents may come from teaching and research institutions in France or abroad, or from public or private research centers.
L'archive ouverte pluridisciplinaire HAL, est destinée au dépôt et à la diffusion de documents scientifiques de niveau recherche, publiés ou non, émanant des établissements d'enseignement et de recherche français ou étrangers, des laboratoires publics ou privés. 


\title{
Inner cladding influence on large mode area photonic crystal fiber properties under severe heat load
}

\author{
E. Coscelli ${ }^{1}$, F. Poli ${ }^{1}$, R. Dauliat ${ }^{2.3}$, D. Darwich ${ }^{2}$, A. Cucinotta ${ }^{1}$, S. Selleri ${ }^{1}$, K. Schuster ${ }^{3}$, A. Benoît ${ }^{2}$, R. Jamier ${ }^{2}$, \\ P. Roy ${ }^{2}$, F. Salin ${ }^{4}$ \\ ${ }^{1}$ Information Engineering Department, University of Parma, I-43124 Parma, Italy \\ ${ }^{2}$ Univ. Limoges, CNRS, XLIM, UMR 7252, F-87000 Limoges, France \\ ${ }^{3}$ Leibniz Institute of Photonic Technology, D-07745 Jena, Germany \\ ${ }^{4}$ EOLITE Systems, F-33600 Pessac, France
}

In the last years, the significant development of high power fiber lasers has been driven by the advantages provided by Yb-doped double-cladding Photonic Crystal Fibers (PCFs) in terms of very large mode area, strong pump absorption, efficient conversion and robust single-mode regime [1]. A further power scaling of fiber lasers, continuously required by practical applications, is currently hindered mainly by thermal effects, which negatively affect the single-mode behavior of Large Mode Area (LMA) PCFs. In fact, beyond a certain average power threshold, the confinement in the fiber core of the Higher-Order Modes (HOMs) improves and an unwanted energy transfer from the Fundamental Mode (FM) occurs [2], causing degradation of the beam quality.

In this work, the influence of the main inner cladding characteristics on the first HOM confinement in Yb-doped LMA PCFs under severe heat load has been investigated. The air-cladding inner dimension and the air-hole diameter, that is the size and the air-filling fraction of the inner cladding, have been modified in order to study which conditions facilitate the coupling between HOMs and cladding modes, thus improving the HOM delocalization and making the fiber single-mode behavior more robust. The effectiveness of the inner cladding in filtering out the HOMs has been studied in different heating conditions, thus showing also which heat load value causes a thermally-induced refractive index change high enough to radically modify the PCF guiding mechanism. Simulation results obtained with a Symmetry-Free PCF (SF-PCF) are presented in this abstract, while a more complete series of data, including those calculated for Large Pitch Fibers, will be shown at presentation time.

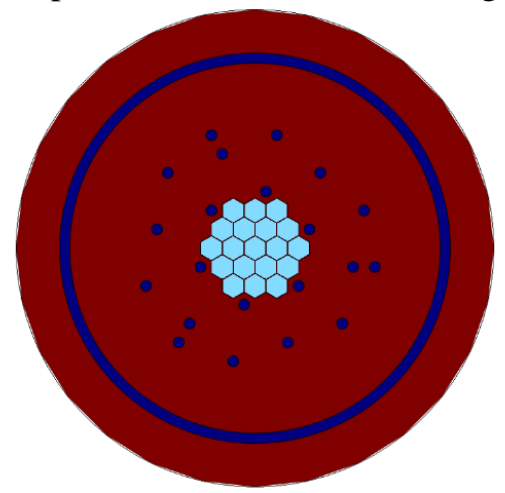

Figure 1: Cross-section of the considered SF-PCF (red: silica, with index 1.45; cyan: Yb-doped silica, with index 1.45; blue: air, with index 1)
As shown by the cross-section reported in Fig. 1, the double-cladding Ybdoped rod-type SF-PCF considered in the present analysis is built over a triangular lattice stack with pitch $\Lambda=15 \mu \mathrm{m}$. The core, formed by replacing the 19 innermost cells with index-matched Yb-doped rods, is surrounded by air-holes with diameter $d$, distributed according to a $\mathrm{C}_{3}$ symmetry, thus breaking the $\mathrm{C}_{60}$ one typical of the triangular lattice. The inner cladding is enclosed by an air cladding with inner diameter $d_{A C}$ and thickness of $7 \mu \mathrm{m}$. 150 modes of the SC-PCF at a wavelength of 1032 have been calculated for heat load $q$ values between $0 \mathrm{~W} / \mathrm{m}$ to $100 \mathrm{~W} / \mathrm{m}$ with a commercial full-vector modal solver based on the finite element method [3], used also to solve the steady-state heat equation. Details on the calculation of the thermallyinduced refractive index change over the fiber cross-section can be found in [4]. Simulation results obtained for SF-PCFs with $d / \Lambda=0.5$ and $d_{A C}$ in the range between $15 \Lambda$ and $21 \Lambda$ are shown in this abstract.

Fig. 2 shows the difference between the calculated mode effective index, $n_{\text {eff }}$, and the FM one, $n_{\text {eff, FM }}$, chosen as a reference, as a function of the heat load $q$ for the SF-PCFs with different air cladding diameter. Notice that, since $n_{\text {eff, } F M}$ increases with the highest slope as heating becomes more severe, all the curves of the other modes, except the reference one, have a negative slope. Moreover, the cladding mode curves are steeper, since their effective index increases with $q$ slower than the guided mode one. It is important to underline that the first HOM curve can be easily identified under high heat load, while it merges with the cladding mode ones, forming a sort of "cloud", for low $q$ values. In fact, starting from the maximum heating condition, that is $q=100 \mathrm{~W} / \mathrm{m}$, as the heat load decreases, the first HOM field confinement in the fiber core worsens and it starts to spread in the inner cladding. By comparing results reported in Fig. 2(a)-(d), it is possible to notice that the cladding mode curves becomes more overlapping and steeper, when the air cladding dimension increases from $15 \Lambda$ to $21 \Lambda$. This change has a direct impact on the first HOM delocalization, which is effective up to a maximum heat load value, called $q_{\max }$, which almost corresponds to the crossing between the HOM curve and the "cloud" of the cladding modes. Notice that $q_{\max }$ becomes lower as the inner cladding diameter 
enlarges, being around $13 \mathrm{~W} / \mathrm{m}, 21 \mathrm{~W} / \mathrm{m}, 26 \mathrm{~W} / \mathrm{m}$ and $28 \mathrm{~W} / \mathrm{m}$ for the fiber with $d_{A C}=15 \Lambda, 17 \Lambda, 19 \Lambda$ and 214 , respectively. The electric field modulus distribution of the HOM at $q_{\max }$ for the different SC-PCFs considered in the analysis is reported in Fig. 3. It is important to underline that the HOM overlap integral on the doped core is about 0.25 when the heat load is $q_{\max }$, regardless of the air cladding inner diameter. Simulation results regarding effective area and overlap integral of FM and HOM on the doped core, as well as a complete discussion on the fiber single-mode regime, will be shown at presentation time.

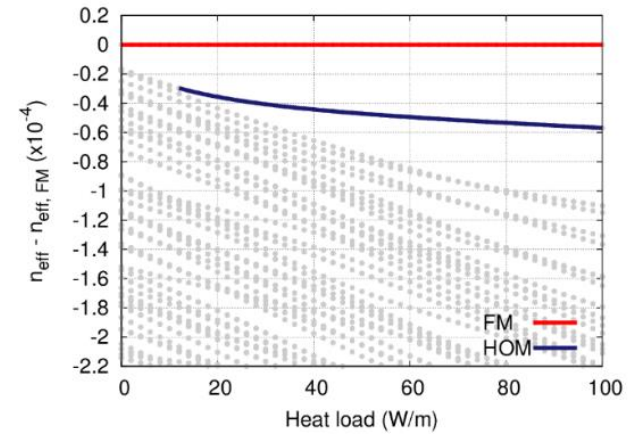

(a)

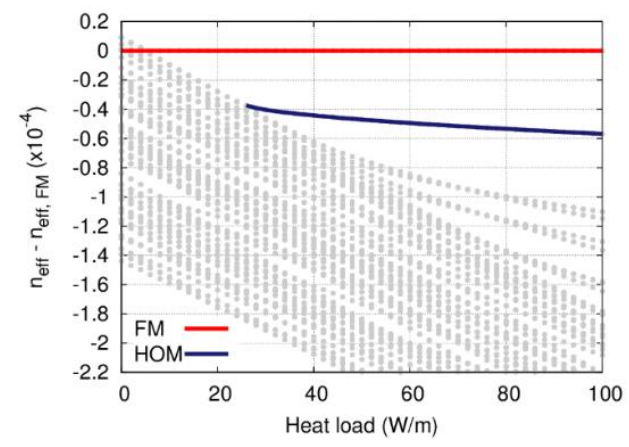

(c)

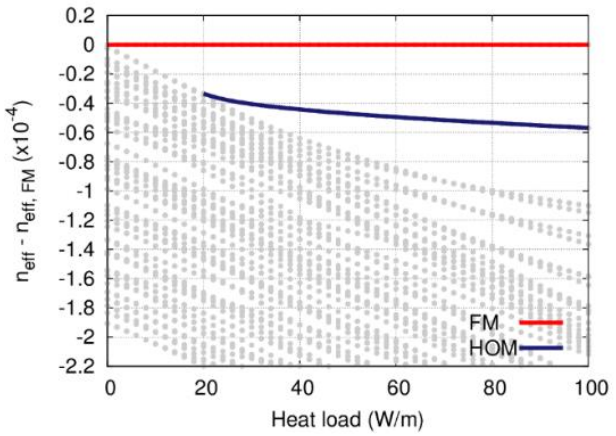

(b)

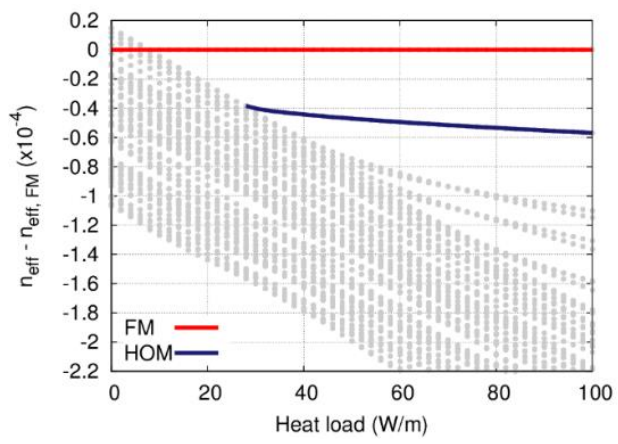

(d)

Figure 2: Difference between the generic mode effective index, $n_{\text {eff, }}$ and the FM one, $n_{\text {eff,FM, }}$ as a function of the heat load $q$ for the SF-PCF with (a) $d_{A C}=15 \Lambda$, (b) $d_{A C}=171$, (c) $d_{A C}=191$ and (d) $d_{A C}=211$.

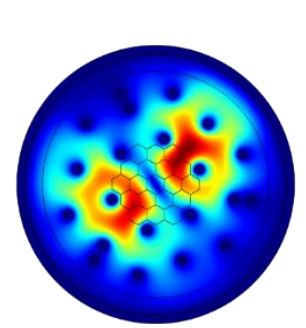

(a)

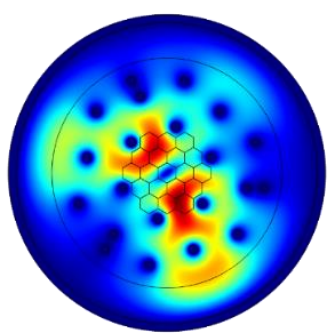

(b)

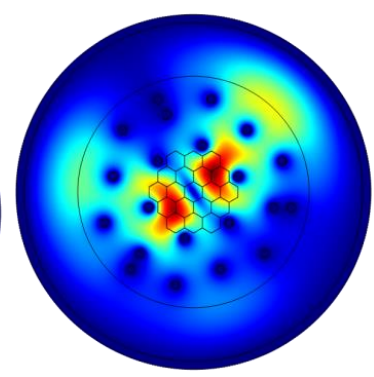

(c)

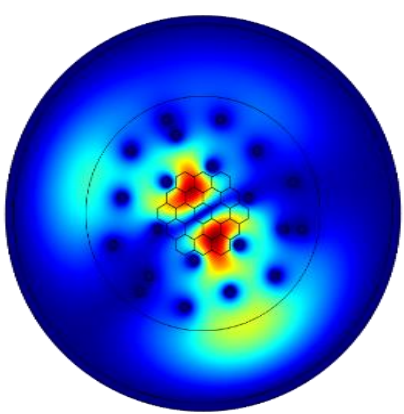

(d)

Figure 3: Electric field modulus distribution of the first HOM at $q_{\max }$ for the SF-PCF with $(a) d_{A C}=15 \Lambda,(b) d_{A C}=174,(c)$ $d_{A C}=191$ and $(d) d_{A C}=211$

\section{References:}

1. M. N. Zervas and C. A. Codemard, "High power fiber lasers: a review," IEEE Journal of Selected Topics in Quantum Electronics, vol. 20, 0904123, September-October 2014

2. K. R. Hansen, T. T. Alkeskjold, J. Broeng, and J. Lægsgaard, "Thermally induced mode coupling in rare-earth doped fiber amplifiers," Optics Letters, vol. 37, pp. 2382-2384, June 2012

3. COMSOL Multiphysics 4.3

4. R. Dauliat, E. Coscelli, F. Poli, D. Darwich, A. Benôt, R. Jamier, K. Schuster, S. Grimm, A. Cucinotta, S. Selleri, F. Salin, and P. Roy, "Large mode area aperiodic fiber designs for robust singlemode emission under high thermal load,” in Proc. SPIE, vol. 9507, pp. 9507-1-9507-11, 2015 